\title{
Argon-37 emanation rates determined for irradiated dry and wet rock samples
}

\author{
STEPHANIE LISA MUSY, SAVERIO BRACCINI, GAIA \\ DELLEPIANE, PIERLUIGI CASOLARO AND ROLAND \\ JOSEF PURTSCHERT
}

University of Bern

Presenting Author: stephanie.musy@climate.unibe.ch

Argon-37 $\left(\mathrm{t}_{1 / 2}=35\right.$ days $)$ is a noble gas isotope that can be used for dating young groundwater e.g. river water recharge in alluvial aquifers[1] but also has potential to act as a neutron flux monitor for the assessment of underground production of ${ }^{39} \mathrm{Ar}[2]$. Both applications are based on the production of ${ }^{37} \mathrm{Ar}$ by activation of $\mathrm{Ca}$ by thermal neutrons $\left({ }^{40} \mathrm{Ca}(n, a)^{37} \mathrm{Ar}\right)$. For the determination of the secular equilibrium activity in the water phase the radioisotope production in the rock and the releasemechanism and -probability need to be quantified[3], [4]. The first can be calculated whereas the latter depends on factors difficult to constrain such as the rock mineralogy, grain size and shape, and water content. Here we present laboratory experiments where aquifer material, ranging from powders to pebbles are irradiated by thermal neutrons produced in a medical cyclotron [5] in order to constrain the dominant release mechanism (recoil vs. diffusive) as function of rock/soil type, but also the effect of water as a moderator of recoiled atoms. This paper presents the experimental setup from neutron irradiation, ${ }^{37} \mathrm{Ar}$ recovery and purification to activity measurement by low level counting. Repeated measurements of samples after storage of several weeks indicate the dominance of recoil over diffusive release. Emanation factors determined for powders (rock pulverized $<63 \mu \mathrm{m}$ ) agree with theoretical estimates assuming a recoil range of $0.3 \mu \mathrm{m}$ [6]. Emanation factors for larger samples (pebbles) can only be interpreted considering the internal network of micro and nanopores. Preliminary experiments with wet samples indicate an enhanced release in comparison to dry samples. We conclude emanation rates in the range $2-8 \%$. Our methodology is a first step towards the experimental determination of emanation rates of ${ }^{39} \mathrm{Ar}$ in rocks.

[1] O. S. Schilling et al. (2017) Water Resources Research.

[2] W. M. Edmunds (2014), Applied Geochemistry.

[3]R. Purtschert et al. (2021), Geochimica et Cosmochimica Acta.

[4]C. Johnson et al. (2018) Journal of Radioanalytical and Nuclear Chemistry.

[5]S. Braccini (2016), Proceedings of Cyclotrons' 16.

[6] R. L. Fleischer (1983), Geochimica et Cosmochimica Acta. 